\title{
Immunomodulation of Potent Antioxidant Agents: Preclinical Study to Clinical Application in Multiple Sclerosis
}

\author{
Shyi-Jou Chen ${ }^{1,2}$ Hueng-Chuen Fan ${ }^{1}$ and Huey-Kang Sytwu2,,* \\ ${ }^{1}$ Department of Pediatrics, Tri-Service General Hospital \\ ${ }^{2}$ Department of Microbiology and Immunology \\ National Defense Medical Center \\ Taiwan (ROC)
}

\section{Introduction}

Multiple sclerosis (MS) is a chronic disease of the central nerve system (CNS) primarily affecting youngsters. The CNS has a potent antioxidant defense mechanism to scavenge reactive oxygen species (ROS). MS can be effectively studied in animal models with experimental autoimmune encephalomyelitis (EAE). The immunopathogenic mechanisms involved in EAE are attributed to T-cell-mediated inflammatory disease of the CNS and activation of $\mathrm{T}$ cells, which recruit invading inflammatory cells, such as macrophages. The activated $\mathrm{T}$ cells also induce astrocytes and microglia in situ to secrete cytokines, chemokines, and toxic molecules, namely, glutamate, nitric oxide (NO), and/or ROS, which in turn contribute to axonal damage. These processes are followed by complement activation and antibody-mediated phagocytosis of axons, which eventually lead to demyelination and axonal injury.

Brain tissue of MS patients was found to express antioxidants, and MS lesions have been reported to express high levels of antioxidants, indicating oxidative stress (OS). Heme oxygenase-1 (HO-1) is a heat-shock protein induced by OS; this protein was found to be expressed in active MS lesions and in EAE. Therefore, it can be inferred that ROS may play a distinct role in the pathogenesis of MS and that antioxidants may inhibit the development and progression of MS lesions. In this chapter, we summarize immunomodulation and therapeutic strategies in MS and examine experimental and clinical evidence to assess the applicability of the novel strategy of using antioxidants, such as melatonin, statins, a-lipoic acid (ALA), natural compounds (flavonoids), and erythropoietin (EPO), as adjuvant treatment in MS.

\section{Roles of OS in MS}

The initial stages of the formation of MS lesions are primarily characterized by the activation of residential microglia by autoreactive Th cells, while the active phase of the MS lesion is

\footnotetext{
${ }^{*}$ Corresponding Author

Conflict of interest: The authors declare that no conflict of interest exist
} 
characterized by the infiltration of the lesion area by monocyte-derived macrophages, which initiate demyelination [Schreiner et al., 2009; van der Valk and De Groot, 2000]. Both activated microglia and infiltrated macrophages can generate excessive amounts of proinflammatory mediators and oxidizing radicals, such as superoxide, hydroxyl radicals, hydrogen peroxide, and NO [Colton and Gilbert, 1993; Gilgun-Sherki et al., 2004]. MS is most commonly studied in animal models of EAE. The immunopathogenesis of EAE is widely believed to involve T-cell-mediated inflammatory disease of the CNS, wherein activated $\mathrm{T}$ cells recruit macrophages and resident astrocytes and microglia, leading to the release of inflammatory mediators and cytotoxic molecules, namely, glutamate, NO, and/or ROS, which contribute to axonal damage; this is then followed by complement activation or antibody-mediated phagocytosis of axons [Hisahara et al., 2003; Schreibelt et al., 2007]. Furthermore, axonal degeneration in MS lesions can be divided into 2 steps: an initial stage of acute axonal injury in the inflammatory MS lesion [Ferguson et al., 1997; Trapp et al., 1998] and subsequent "slow burning" or axonal degeneration in non-inflammatory chronic lesions [Kornek et al., 2000]. The pathological changes in MS are also characterized by the presence of demyelinating plaques within the gray matter [Frohman et al., 2006]. Nevertheless, mitochondrial dysregulation and mitochondria-derived ROS have been reported to contribute to axonal damage in MS [Kalman et al., 2007; Mahad et al., 2009; Su et al., 2009; van Horssen et al., 2010; Witte et al., 2009]. In addition, a subset of activated microglia was found in cortical lesions, suggesting that microglia-derived ROS might contribute to gray matter demyelination [Gray et al., 2008]. Taken together, these evidences indicate that ROS play a pivotal role in several processes underlying the formation and persistence of MS lesions.

Experimental animal studies have demonstrated that the dietary intake of exogenous antioxidants, including flavonoids and a-lipoic acid, reduces the progression and clinical signs of EAE [Chaudhary et al., 2006; Hendriks et al., 2004; Marracci et al., 2002; Theoharides, 2009; Verbeek et al., 2005]. Despite promising results observed in animal models of MS, data on successful antioxidant therapy in MS patients is still limited; this emphasizes the need for epidemiological and clinical studies on this treatment strategy in MS. Reports indicate that antioxidants need be administered in high quantities to exert their protective effects in animal models of MS [Gilgun-Sherki et al., 2004; Mirshafiey and Mohsenzadegan, 2009]. Since ROS play a pivotal role in the initial phase as well as the chronic stage of MS, antioxidant therapy may be suitable for limiting overall disease progression. Thus, further understanding of the immunomodulatory activities of potential protective antioxidants is vital for their application in MS [Schreibelt et al., 2007; van Horssen et al.].

\subsection{HO-1 in EAE/MS}

HO-1 is a heat-shock protein induced by OS. In HO-1-expressing cells, the association of reductase with HO-1 competitively limits the interaction of reductase with cytochrome P450 isozymes, and thereby, the resultant production of superoxide; this reduced interaction limits free radical production and prevents oxidative damage of DNA, thereby suppressing oxidative or proinflammatory tissue damage [Prawan et al., 2005]. HO-1 has both antioxidative and anti-inflammatory activities and is highly inducible by a variety of stimuli, including its substrates heme and OS [Schipper, 2004]. Lee and Chau demonstrated that the 
overexpression of HO-1 in macrophages can inhibit proinflammatory response via lipopolysaccharide (LPS) stimulation and that IL-10 and HO-1 activate a positive feedback circuit to enhance the anti-inflammatory response both in vitro or in vivo [Lee and Chau, 2002]. In addition, Ponomarev et al. found that increased expression of IL-4 in glial cells was associated with reduced severity of EAE and that IL-4 production in the CNS is crucial for controlling autoimmune inflammation by inducing an alternative pathway for the regulation of microglial cells, but IL-4 production in the peripheral circulation was not found to have this effect [Ponomarev et al., 2007]. In contrast, Lee and Suk showed that IL10 and IL-4 levels did not have any effect on the overexpression of HO-1 in LPS-stimulated microglia in vitro [Lee and Suk, 2007]. However, Zenclussen et al. found that the upregulation of HO-1 by using an adenoviral vector system expressing the HO-1 gene (AdHO-1) has a protective effect against fetal rejection in the murine abortion model; they also found that compared to abortion-prone mice, AdHO-1-treated mice showed higher values of the systemic and local IL-4/IFN-Y ratios and the IL-10/TNF- $\alpha$ ratio in the spleen [Zenclussen et al., 2006].

HO-1 has been detected in EAE lesions, and significant amplification of HO-1 protein levels has been proved in animal models of EAE [Schluesener and Seid, 2000]. HO-1 expression has also been reported in active MS lesions [van Horssen et al., 2008]. This enhanced expression of endogenous HO-1 may be one of the mechanisms involved in minimizing tissue damage in EAE [Emerson and LeVine, 2000]. Evidence has also shown that Hmox1(/- )C57BL/6 mice, i.e., HO-1 gene knockout mice, displayed greater severity of EAE as compared to Hmox1(+/+) mice. Further, induction of HO-1 by cobalt protoporphyrin IX (CoPPIX) administration has been shown to suppress EAE progression, but this protective effect of CoPPIX was abrogated in Hmox1(-/-) mice with EAE [Chora et al., 2007]. Thus, endogenous HO-1 expression may play an important protective role in EAE, and therefore, the induction of HO-1 overexpression may represent a novel therapeutic strategy for MS [Liu et al., 2001].

\subsection{Inflammation and immunopathogenesis of ROS and NO in MS}

Brain tissue is very vulnerable to free radical damage because of its high oxygen utilization ( $20 \%$ of the total oxygen inspired); high concentrations of polyunsaturated fatty acids [Floyd and Hensley, 2002] and transition metals, such as iron, which are involved in the generation of the hydroxyl radical [Hill and Switzer, 1984]; and low concentrations of cytosolic antioxidants [Floyd and Carney, 1993; Reiter, 1995b]. In the brain, NO plays crucial roles in neuromodulation, neurotransmission, maintenance of synaptic plasticity, etc., and it also mediates pathological processes such as neurodegeneration and neuroinflammation [Golde et al., 2002]. Thus, NO may inhibit neuronal respiration, and NO production by astrocytes is believed to contribute to the neurodegenerative process via the impairment of mitochondrial function.

In addition, neuronal injury has also been reported to be associated with NO released by glial cells [Bal-Price and Brown, 2001; Mander et al., 2005]. Although glial activation can be protective, excess activation can be detrimental [Murphy, 1999]. Glia are activated by inflammatory mediators and express new proteins such as inducible NO synthatase (iNOS) [Emerit et al., 2004]. NO produced by the action of iNOS appears to be a key mediator of 
glia-induced neuronal death. Astroglial cells are "activated" in a wide range of CNS disorders, leading to the induction of iNOS [Bolanos et al., 1997; Endoh et al., 1994]. In mouse models of EAE, immunohistochemistry revealed elevated activity levels of iNOS in inflammatory lesions of the CNS, suggesting that excessive NO production due to activity of iNOS may play an essential role in eradicating inflammatory cells in the CNS of mice with EAE [Okuda et al., 1997].

A chronic inflammatory state gives rise to an activated immune response, which involves an acute phase protein response and the release of proinflammatory cytokines, macrophages, lymphocytes, and other immune system cells [Murakami, 2009; Taupin, 2008]. This complicated process triggers the recruitment of innate immune cells, which in turn mediates demyelination and axonal damage, and the formation of lesions that generally consist of $\mathrm{T}$ cells, macrophages, and microglia. OS plays a critical role in the pathogenesis of MS. ROS, which are generated in excess amounts mainly by macrophages subjected to OS, have been implicated in the demyelination and axonal damage occurring in both MS and EAE [GilgunSherki et al., 2004]. NO has also been identified in the spinal cords of mouse models of EAE, indicating the potential role of $\mathrm{NO}$ in the pathogenesis of EAE, and possibly MS [Lin et al., 1993].

Increased levels of the indicators of OS and/or decreased levels of antioxidant enzymes and antioxidants have been detected in the blood and cerebrospinal fluid of MS patients in the active phases of the disease; these findings indicate that increased levels of ROS may cause the depletion of cellular antioxidants [van der Goes et al., 1998; van Horssen et al., 2010; van Meeteren et al., 2005]. In recent decades, immunologic cascade and inflammation have been proposed as causative factors of neurological diseases and autoimmune disorders, such as MS [Taupin, 2008]. On the basis of currently available findings, we assessed the usefulness of statins, melatonin, ALA, natural antioxidant compounds, and EPO, as potential candidates for adjuvant therapy in MS patients, by virtue of for their antioxidant and immunomodulatory proprieties.

\section{Statins in MS/EAE}

The 3-hydroxy-3-methylglutaryl coenzyme A (HMG-CoA) reductase inhibitors (or statins) are powerful cholesterol-lowering drugs, which are beneficial to the primary and secondary prevention of coronary heart disease; these drugs can improve endothelial function, increase NO bioavailability, exhibit antioxidant activity, stabilize atherosclerotic plaques, regulate progenitor cells, inhibit inflammatory responses, and exert immunomodulatory effects [Endres, 2006]. Pahan et al. reported that lovastatin inhibits the induction of iNOS and expression of proinflammatory cytokines in rat primary glial cells (astroglia and microglia) and macrophages [Pahan et al., 1997]. Subsequently, Stanislaus et al. showed that proinflammatory cytokines and iNOS are involved in the pathogenesis of EAE [Stanislaus et al., 1999] and thus highlighted the therapeutic importance of lovastatin in inhibiting the neuroinflammatory processes in the CNS and the central expression of iNOS, TNF-a, and IFN- $\gamma$ in EAE; this suggests that lovastatin may have therapeutic potential in the treatment of neuroinflammatory diseases, such as MS [Stanislaus et al., 1999].

Atorvastatin exhibits pleiotropic immunomodulatory activity against both antigenpresenting cells (APC) and T-cell compartments. For instance, Youssef et al. reported that 
atorvastatin treatment of microglia inhibits IFN- $\gamma$-inducible transcription of multiple major histocompatibility complex (MHC) class II transactivator (CIITA) promoters and suppresses the upregulation of class II MHC [Youssef et al., 2002]. In addition, they found that atorvastatin suppresses IFN- $\gamma$-inducible expression of CD40, CD80, and CD86 costimulatory molecules, as well as L-mevalonate, thereby indicating that statins may be beneficial in the treatment of MS and other Th1-mediated autoimmune diseases [Youssef et al., 2002].

Nath et al. demonstrated that lovastatin inhibits EAE by modulating T-cell as well as APC responses and that the effects of lovastatin on macrophage/microglia in an Ag-non-specific system suggest that lovastatin is not only effective in EAE. Their study also revealed that lovastatin inhibits the transcription factors T-bet, NF-kB, and STAT4, which are responsible for CNS inflammation, via the induction of Th1 cell differentiation and production of related cytokines, such as IFN- $\gamma$ and TNF- $\alpha$. In addition, lovastatin induces the expression of GATA3 and STAT6 in Th2 cells and contributes to the downregulation of IFN- $\gamma / \mathrm{T}-$ bet in Th1 cells [Nath et al., 2004]. Statins have been reported to have potential for use as novel therapeutic agents to reverse the established paralysis in MS and to exert beneficial effects in synergy with other agents already approved for MS therapy [Weber and Zamvil, 2008]. However, simvastatin administered along with interferon $\beta$-1a as add-on therapy for at least 1-3 years in patients with relapsing-remitting MS (SIMCOMBIN study) did not show any beneficial effects in a placebo-controlled randomized phase 4 clinical trial [Sorensen et al.]. Similarly, a cohort study revealed that the disability progression in MS did not differ significantly between MS patients receiving and those not receiving statin therapy, thereby suggesting that statins do not affect the long-term course of MS [Paz Soldan et al.]. However, the combination of other statins with other disease-modifying drugs may be beneficial in MS. More clinical data is required to clarify this issue.

\section{Melatonin in MS/EAE}

Melatonin (5-methoxy- $N$-acetylserotonin) is mainly produced in the pineal gland during the dark phase of the day-night cycle, and it displays multifunctional properties and characteristics of a potent antioxidant [Martin et al., 2000]. In addition, melatonin is involved in the regulation of aging [Pierpaoli and Regelson, 1994] and scavenging of free hydroxyl radicals [Reiter, 1995a]. Melatonin is now well-known as a powerful antioxidant; an increasing number of experimental evidences have shown its protective effects against OSinduced macromolecular damage and diseases, including those involving mitochondrial dysfunction [Acuna et al., 2002]. Furthermore, melatonin exhibits both direct and indirect antioxidant activity, scavenges free radicals, stimulates antioxidant enzymes, enhances the activities of other antioxidants, and protects other antioxidant enzymes from oxidative damage [Castroviejo et al., 2011; Esposito and Cuzzocrea, 2010].

The results of numerous clinical studies have indicated that melatonin is a neuroprotective molecule in neurodegenerative disorders, which are believed to involve widespread brain oxidative damage [Esposito and Cuzzocrea, 2010; Kaur and Ling, 2008]. For example, melatonin defeats neurally derived free radicals and reduces the associated neuromorphological and neurobehavioral damage [Reiter et al., 2007]. Melatonin inhibits the expression of the iNOS in murine macrophages by inhibiting NF-kB activation [Gilad et al., 1998] and suppressing the levels of intercellular adhesion molecule (ICAM)-1 in 
experimental spinal cord reperfusion injury [Cuzzocrea et al., 2000]. Constantinescu et al reported that melatonin is capable of immunomodulation via the activation of NK cells [Constantinescu et al., 1997], upregulation of Th2 response, and inhibition of NF-KB [Maestroni, 1995]. Thus, both experimental and clinical data show that melatonin reduces the expression of adhesion molecules and pro-inflammatory cytokines and modifies serum inflammatory parameters.

Since the abovementioned findings indicate that melatonin exhibits both anti-inflammatory and immunomodulatory activities, it can be considered effective in suppressing autoimmune diseases, including EAE [Constantinescu, 1995; Sandyk, 1997]. Moreover, Kang et al. demonstrated that melatonin ameliorates EAE through the suppression of ICAM-1 levels. They also reported that melatonin treatment increases T-cell proliferation in mice and enhances the production of NK cells and monocytes in the bone marrow of mice, suggesting that it plays an important role in the immune system; thus, exogenous melatonin has been shown to ameliorate EAE by reducing the expression of ICAM-1 and lymphocyte functionassociated antigen-1a (LFA-1a) in autoimmune target organs [Kang et al., 2001]. On the other hand, Maestroni et al. showed that melatonin treatment of mice decreases the expression of IL-2 and IFN- $\gamma$ and upregulates the expression of Th2 cell cytokines, such as IL-4 and IL-10 [Maestroni, 1995]. Lin et al. found that melatonin prolongs islet graft survival in nonobese diabetic (NOD) mice via the reduction of Th1 cell and T-cell proliferation and elevating IL-10 levels, thereby indicating that melatonin treatment suppresses autoimmune recurrence after graft implantation [Lin et al., 2009]. Thus, melatonin plays a role in immunomodulation by regulating cytokine production of immunocompetent cells. From these findings, melatonin may be considered effective in improving the clinical course of autoimmune inflammatory diseases.

A clinical study by Akpinar et al. revealed that nocturnal serum melatonin levels were associated with major depression in acute MS patients, suggesting that melatonin deficiency may contribute to the occurrence of depression in MS patients [Akpinar et al., 2008b]. Moreover, Anderson et al. demonstrated that the optimization of melatonin and vitamin D3 inhibits the effects of IL-18 on the symptoms and cell loss of MS, as well as microglia and Tcell activation [Anderson and Rodriguez, 2011]. In addition, they confirmed that valproate treatment may interact significantly with melatonin and vitamin D3 to inhibit seizures and other signs and symptoms of MS [Anderson and Rodriguez, 2011]. Thus, the understanding of the immunomodulatory and anti-oxidative activity of melatonin in EAE may enable the therapeutic application of this molecule in MS.

\section{ALA in MS/EAE}

ALA (or 1,2-dithiolane-3-pentanoic acid) is a naturally occurring dithiol compound synthesized enzymatically in the mitochondrion from octanoic acid (Curr. Med. Chem. 11 (2004) 1135-1146.); it is an essential cofactor of key mitochondrial enzymes that control glucose oxidation, such as pyruvate dehydrogenase and a-ketoglutarate dehydrogenase [Gohil et al., 1999]. ALA mainly acts as a natural antioxidant that scavenges ROS and regenerates or recycles endogenous antioxidants (Free Radic. Res. 20 (1994) 119-133.). ALA and its reduced dithiol form, dihydrolipoic acid (DHLA), are potent antioxidants in both fatand water-soluble media. In addition, ALA reacts with superoxide and hydroxyl radicals, hypochlorous acid, peroxyl radicals, and singlet oxygen [Marangon et al., 1999]. ALA also 
recycles vitamins $\mathrm{C}$ and $\mathrm{E}$ and increases the intracellular glutathione concentration. The antioxidative effect of ALA may be partially mediated by the chelation of transition metals, modification of the redox status of thiol-containing proteins, and inhibition of redoxsensitive nuclear transcription factors [Abdul and Butterfield, 2007; Akpinar et al., 2008a; Moini et al., 2002]. Tirosh et al. have previously shown that LA-plus is a potent protector of neuronal cells against glutamate-induced cytotoxicity and associated oxidative damage [Tirosh et al., 1999]. Further, Cheng et al. reported that ALA protects the cardiovascular system against oxidative injury` [Cheng et al., 2006]. They also found that ALA significantly increased the expression levels of HO- 1 and ROS production and increased HO activity in A10 cells and the resistance of A10 cells to hydrogen-peroxide-induced OS; this effect was blocked by $N$-acetyl-cysteine, which also inhibited ALA-induced activation of p44/42 mitogen-activated protein kinase (MAPK) and AP-1, HO-1 expression, and $\mathrm{HO}$ activity. These findings suggest that ALA induces HO-1 expression through the production of ROS and subsequent activation of the p44/42 MAPK pathway and AP-1 in vascular smooth muscle cells and that it increases the expression of HO-1, which is a critical cytoprotective molecule [Cheng et al., 2006].

van der Goes et al. reported that ROS appear to be involved in the regulation of the phagocytosis of myelin and that lipoic acid (LA), a non-specific scavenger of ROS, also decreased the phagocytosis of myelin by macrophages [van der Goes et al., 1998].

Marracci et al. have shown that ALA ameliorates EAE in SJL mice immunized with proteolipid protein (PLP) 139-151 peptide, resulting in minimal inflammation characterized by less demyelination and only mild axonal loss in the spinal cords; they also demonstrated a marked reduction in the expression of $\mathrm{CD}^{+} \mathrm{T}$ cells and $\mathrm{CD} 11 \mathrm{~b}^{+}$monocyte/macrophage cells in the affected spinal cord. Further, ALA and its reduced form, DHLA, inhibited the activity of matrix metalloproteinase-9 (MMP-9) in a dose-dependent manner [Marracci et al., 2002]. This was associated with a reduction in the number of CNS-infiltrating $T$ cells and macrophages as well as decreased demyelination. Morini et al. further tested ALA in a therapeutic protocol aimed at suppressing myelin oligodendrocyte glycoprotein (MOG)EAE; they also found significant reduction of demyelination and inflammatory infiltration and in the number of MOG-specific T cells, resulting in decreased production of IFN- $\gamma$ and IL-4; this suggests that ALA exerts immunosuppressive activity on both Th1 and Th2 cytokines [Morini et al., 2004].

Marracci et al. showed that both ALA and DHLA inhibited Jurkat cell migration and have different mechanisms for inhibiting MMP-9 activity. These data together with the finding that ALA can ameliorate relapsing EAE suggest that ALA merits investigation as a therapeutic agent for MS [Marracci et al., 2004]. Moreover, Schreibelt et al. reported that antioxidant LA dose-dependently prevented the clinical development of EAE in a rat model of MS, along with a decrease in the CNS infiltration of leukocytes, particularly monocytes, which may be reflected as reduced ability to cross the blood brain barrier (BBB) [Schreibelt et al., 2006].

Accordingly, oxidative injury is recognized as an important process in the pathogenesis of MS. The powerful antioxidant property of ALA may render it a good candidate for adjuvant treatment in EAE/MS. In addition, ALA is greatly effective in suppressing and treating EAE; this effect is mediated by the inhibition of T-cell trafficking into the spinal cord, 
possibly by inhibiting MMP. Thus, ALA impedes the development of EAE not only by serving as an antioxidant but also by affecting the migratory capacity of monocytes and by stabilizing the BBB; these features make ALA an attractive therapeutic agent for MS

\section{Potential of natural food compounds in the treatment of EAE/MS}

Aktas et al. reported that the green tea extract epigallocatechin-3-gallate (EGCG) reduced the clinical severity of EAE when administered at the initiation or after the onset of the condition; this effect of EGCG is believed to be mediated by the limiting of brain inflammation and reducing neuronal damage, which are mediated by NF-kappa B inhibition, abrogated proliferation and TNF-alpha production of encephalitogenic T cells, and direct blocking of the formation of neurotoxic ROS in neurons [Aktas et al., 2004]. Thus, natural green tea components that have antioxidant, anti-inflammatory, and neuroprotective activities, may be considered novel candidates for the treatment of MS.

\subsection{Natural compounds repress MMP to protect EAE/MS}

Hendriks et al. have shown that flavonoids, which are naturally occurring compounds of green tea, can influence myelin phagocytosis by macrophages in vitro. The flavonoids luteolin, quercetin (3,3'4',5,7-pentahydroxy flavone), and fisetin most significantly reduce the extent of invasion of myelin phagocytes, without affecting their viability; this implies that they may be capable of restricting the demyelination process involved in MS [Hendriks et al., 2003]. On similar lines, Theoharides found that luteolin and structurally similar flavonoids can inhibit EAE and suggested that an appropriate luteolin formulation that permits sufficient absorption and reduces its metabolism could be a useful adjuvant to IFN$\beta$ in the treatment of MS [Theoharides, 2009]. A study by Muthian et al. on SJL/J mouse models of EAE revealed that quercetin (QRC), a flavonoid phytoestrogen, ameliorates EAE in vivo by inhibiting IL-12 production and neural antigen-specific Th1 differentiation and by reducing the MMP-9/TIMP-1 ratio. They further reported that when QRC was used in combination with IFN- $\beta$, it has additive effects on the regulation of the levels of TNF- $\alpha$ and MMP-9 [Sternberg et al., 2008]. The enzymes gelatinases A (MMP-2) and B (MMP-9) are involved in the pathogenesis of MS [Bever and Rosenberg, 1999; Mandler et al., 2001]. Liuzzi et al. reported that the non-flavonoids resveratrol (RSV) and tyrosol/hydroxytyrosol (Oliplus), but not the flavonoids QRC and catechins [green tea extract (GTE)], dosedependently inhibit the expression of MMP-2 and MMP-9 in LPS-activated primary rat astrocytes. In turn, the direct inhibition of MMP2 and MMP-9 was achieved completely by QRC and GTE, not by RSV, and only partially by oliplus in cell-free systems of MS sera. These results indicate that the flavonoids and non-flavonoids tested exert their inhibitory effect on MMPs, displaying different mechanisms of action, possibly related to their structure; this indicates that their combined use may represent a powerful tool for the downregulation of MMPs in the course of MS [Liuzzi et al.].

\subsection{Fumarate linking to Nrf2 pathway to protect MS}

The antioxidant-responsive element (ARE) is an enhancer element that triggers the transcription of a battery of genes encoding phase II detoxification enzymes [Rushmore et al., 1991; Rushmore and Pickett, 1990] and factors vital for neuronal survival [Lee et al., 
2005]. The ARE is activated through the binding of its transcription factor NF-E2-related factor 2 (Nrf2) [Moi et al., 1994; Venugopal and Jaiswal, 1996]. Nrf2-ARE activation is a critical neuroprotective pathway that confers resistance to a variety of oxidative, stressrelated, neurodegenerative injuries [Johnson et al., 2008]. Evidentially, autopsy studies of MS-affected tissue have revealed that neuronal Nrf2 is also activated during the natural course of MS, which is similar to the observations made in untreated EAE [Linker et al.]. Furthermore, van Horssen et al. showed that invading leukocytes contribute to cell damage and demyelination by producing excessive amounts of cytotoxic mediators, including ROS, and that to neutralize the destructive effects of ROS, the CNS is endowed with a repertoire of endogenous antioxidant enzymes, which are regulated by the transcription factor Nrf2; on the basis of these findings, they suggested that persistent Nrf2-mediated transcription occurs in active MS lesions, but this endogenous response is insufficient to prevent ROSinduced cellular damage, which is abundant in inflammatory MS lesions [van Horssen et al.]. Accordingly, overexpression of Nrf2/ARE-regulated antioxidants in EAE and MS tissue is indicative of ongoing OS [Schreibelt et al., 2007]. Furthermore, Linker et al. reported the Nrf2 pathway was activated by dimethyl fumarate or monomethyl fumarate [Linker et al.]. They showed that dimethylfumarate exerts protective effects on oligodendrocytes, myelin, axons, and neurons in vivo and reduces the oxidative stress in MOG-EAE models; their study also provided evidence that the proper functioning of Nrf2 is required for the therapeutic effect of dimethylfumarate, suggesting that the CNS-protective effects of dimethylfumarate involve the activation of Nrf2-mediated OS response mechanisms, which is an important protective mechanism of the CNS in a variety of pathological conditions. A phase II trial is currently underway to examine the applicability of fumarate as a diseasemodifying agent in MS patients [Barten et al., 2010].

\subsection{Other extracts from plants to benefit MS}

De Paula et al. found that genistein, which occurs abundantly in soy products, has apoptotic, antioxidant, and anti-inflammatory properties. They observed that genistein treatment significantly ameliorated the severity of EAE, modulating pro- and antiinflammatory cytokines and decreasing the rolling and adhering of leukocytes, which imply that genistein may have potential as a therapeutic agent for MS [De Paula et al., 2008]. Another antioxidant compound, silymarin - a purified extract from milk thistle (Silybum marianum) - is composed of a mixture of 4 isomeric flavonolignans: silibinin (main active component), isosilibinin, silydianin, and silychristin. This extract has been empirically used as a remedy for almost 2000 years and continues to be used in the treatment of many types of acute and chronic liver diseases. Although it is routinely used in clinical practice as a hepatoprotectant, the mechanisms underlying its beneficial effects remain largely unknown [Crocenzi and Roma, 2006]. Min et al. reported that silibinin significantly reduced the histological signs of demyelination and inflammation in EAE and that silibinin downregulated the secretion of pro-inflammatory Th1 cytokines and upregulated the antiinflammatory Th2 cytokines in vitro in an Ag-nonspecific manner. Further, silibinin dosedependently inhibited the production of Th1 cytokines ex vivo, indicating that it is both immunosuppressive and immunomodulatory and may therefore be effective in the treatment of MS [Min et al., 2007].

Together, many antioxidant components extracted from natural foods or plants, such as flavonoids, luteolin, EGCG (extracted from green tea), genistein (occurring abundantly in 
soy), and silibinin (the major pharmacologically active compound of silymarin, a fruit extract of $S$. marianum) have been proved to have not only health benefits but also the potential for use in the treatment of MS [Hutter and Laing, 1996; Mori et al., 2004; Sueoka et al., 2001; Theoharides, 2009].

\section{Antioxidant and immunomodulatory effects of EPO in MS/EAE}

EPO exhibits both hematopoietic and tissue-protective effects via interaction with different receptors [Leist et al., 2004].

Several experimental studies have shown that both EPO and EPO receptor (EpoR) are functionally expressed in the nervous system and that this cytokine has remarkable neuroprotective activity both in vitro, against different neurotoxicants, and in vivo, in animal models of experimental nervous system disorders [Bartesaghi et al., 2005]. Moreover, EPO has been proved to have the ability to cross the BBB and modulate astrocytes to protect the brain from ischemic damage and the spinal cord from injury in animal models [Bernaudin et al., 1999; Brines et al., 2000; Diaz et al., 2005]. The neuroprotective effects of EPO against neuronal death induced by ischemia and hypoxia have also been extensively studied in both in vitro and in vivo studies [Bernaudin et al., 1999; Gunnarson et al., 2009].

\subsection{Cytoprotective interaction of EPO and HO-1}

A recent report indicated that the upregulation of HO-1 expression contributes to EPOmediated cytoprotection against myocardial ischemia-reperfusion injury [Burger et al., 2009]. The neuroprotective action of EPO in ischemic and CNS degenerative models was mediated by Janus-tyrosine kinase 2 (Jak2) signaling and the subsequent activation of PI3K/Akt phosphorylation and NFKB cascades, which lead to the suppression of the CNS damage due to excitotoxins and the consequent generation of free radicals, including NO [Digicaylioglu and Lipton, 2001; Maiese et al., 2004]. Moreover, Sättler et al. showed that in rats with MOG-induced optic neuritis, the systemic administration of EPO resulted in a significant increase in the survival and function of retinal ganglion cells (RGC), the neurons that form the axons of the optic nerve; they also found that the neuroprotective effects of EPO were mediated by 3 independent intracellular signaling pathways involving the proteins phospho-Akt, phospho-MAPK 1 and 2, and Bcl-2m, which showed increased levels in vivo after EPO treatment [Sattler et al., 2004]. They also found that EPO in combination with a selective inhibitor of phosphatidylinositol 3-kinase (PI3-K) prevented the upregulation of phospho-Akt and the consecutive RGC rescue, thereby indicating that the PI3-K/Akt pathway in MOG-EAE has an essential influence on RGC survival under systemic EPO treatment [Sattler et al., 2004]. Interestingly, PI3K/Aktpathway-related responses to OS and apoptosis have also been shown to be mediated by the transcriptional regulation of HO-1 [Martin et al., 2004]. Previously, Lifshitz et al. demonstrated that the dendritic cells (DCs) are direct targets of EPO, to initiate the immune response through the overexpression of human EPO in transgenic mice in in vivo experiments and validate a higher expression of EPO-R mRNA from bone marrowderived DCs (BM-DCs) [Lifshitz et al., 2009]. Recent reports indicate that EPO exerts its cytoprotective effects in cardiac ischemia-reperfusion injury by inducing HO-1 expression [Burger et al., 2009] 


\subsection{Interaction of EPO, HO-1, and NO in EAE/MS}

Tzima et al. reported that myeloid HO-1 deficiency exacerbated EAE in mice and enhanced the infiltration of activated macrophages and Th17 cells (IL-17-producing CD4 ${ }^{+}$IL-17producing $\mathrm{CD}^{+} \mathrm{T}$ cells) in the CNS, and thus, they established HO-1 as a critical early mediator of the innate immune response [Tzima et al., 2009; Zwerina et al., 2005]. Liu showed that the inhibition of HO-1 expression resulted in marked exacerbation of EAE, suggesting that endogenous HO-1 expression plays an important protective role in EAE and that the targeted induction of HO-1 overexpression may represent a novel therapeutic strategy for the treatment of MS [Liu et al., 2001]. A study be Wu et al. at a center associated with ours revealed that the therapeutic induction of HO-1 expression ameliorates experimental murine membranous nephropathy via anti-oxidative, anti-apoptotic, and immunomodulatory mechanisms [Wu et al., 2008]. HO-1 overexpression has been proved to protect cells and tissues in a transgenic model of EAE [Panahian et al., 1999]. Moreover, Kumral et al. demonstrated that EPO exerts neuroprotective activity through the selective inhibition of NO overproduction in neonatal hypoxic-ischemic brain injury [Kumral et al., 2004]. Furthermore, Yuan et delineated a novel potential of EPO on peripheral inflammatory modulation in a murine MOG-EAE model [Yuan et al., 2008].

\subsection{Immunomodulatory effects of EPO in EAE}

After EPO was found to have neuroprotective effects in murine models of EAE [Zhang et al., 2005], it was introduced in humans and found to be effective in chronic progressive MS [Ehrenreich et al., 2007]. In our previous study, we found that EPO can enhance the expression of endogenous HO-1 either peripherally or locally in EAE; similarly, we observed that EPO-treated MOG-EAE mice exhibited upregulation of the splenic regulatory $\mathrm{CD}^{+} \mathrm{T}$ cells (Treg) and Th2 cells and downregulation of central Th1 and Th17 cells. We also obtained molecular evidence proving that EPO enhances the expression of endogenous HO1 and that it has potential immunomodulatory activity and causes the suppression of inflammatory response to EAE [Chen et al., 2010].

We thus demonstrated the protective effects of EPO on EAE (Fig. 1a, b), and we observed significantly higher expression levels of endogenous HO-1 mRNA in the brain and a tendency for higher expression levels of endogenous HO-1 mRNA in the spinal cord and brain of the EPO-treated MOG-EAE mice than in those of the controls (Fig. 1c). Similarly, the expression levels of HO-1 mRNA in lymphocytes isolated from the CNS of MOG-EAE mice and controls differed significantly (Fig. 1c). Correspondingly, the protein levels of HO-1 in the spinal cord of EPO-treated MOG-EAE mice were higher than those of the controls (Fig. 1d). We further confirmed the augmenting effects of EPO on HO-1 in situ. Encephalitogenic Th17 cells play an essential role in the pathogenesis of EAE [Bettelli et al., 2006]. Th1 cells facilitate the invasion of Th17 cells to the CNS during EAE [O'Connor et al., 2008]. Further, IL-4 produced by CNS-derived Th2 cells is crucial to regulate the inflammation in EAE [Ponomarev et al., 2007]. To study the Th lineages further, we isolated mononuclear cells from the CNS of MOG-EAE mice treated with EPO and controls. Interestingly, we observed significantly lower ratios of both Th1 and Th17 cells to CD4+ cells in the EPO-treated MOGEAE mice than in the controls; only a mildly increasing trend of encephalitogenic Th2 cells $/ \mathrm{CD}^{+}$cells was noted in the EPO-treated group (Fig. $2 \mathrm{a}-\mathrm{b}$ ). These findings suggest that EPO has the ability to counteract encephalitogenic Th1 and Th17 cells in situ, at least in part, and protect neuronal cells in EAE. 
(a)

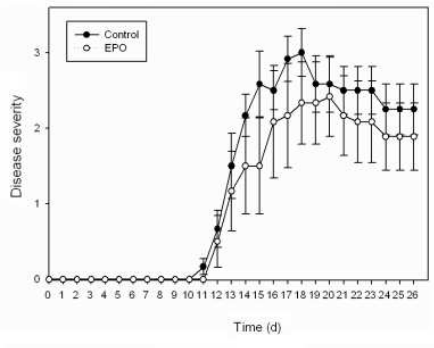

(b)

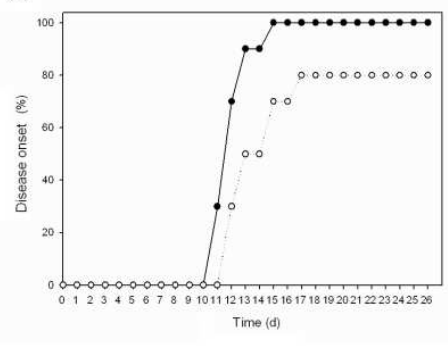

(d)

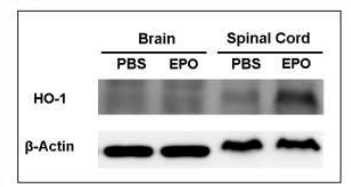

(c)
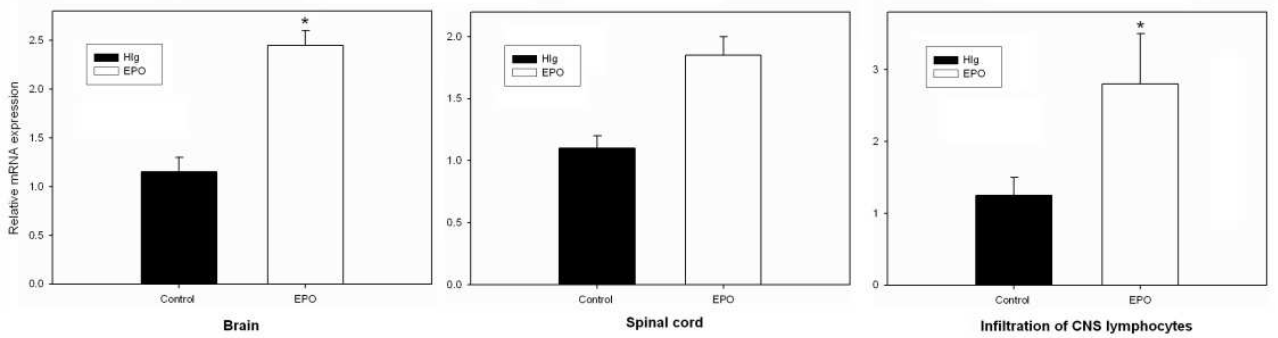

Fig. 1. EPO lessens EAE and enhances HO-1 in situ. (a) Clinical score and (b) time of onset of EAE in C57BL/ 6 mice treated i.p. with PBS or EPO (100 U/100 $\mu \mathrm{l} /$ mouse $)$ on days 1, 3, 5, and 7 after s.c. immunization with MOG $35-55 / C F A$ on day 0 and PTX i.p. on days 0 and 2. Each group contained 10 mice. Data represent means \pm SEM. (c) Expression of HO-1 mRNA in the brain, spinal cord, or lymphocytes isolated from CNS of EPO-treated and PBS-treated (as control) MOG-EAE mice determined by real time PCR. Data in plots are expressed as mean \pm SD from 3 independent experiments. Statistical significance was set at $p<0.05$. (d) Western blot analysis of HO-1 expression in the brain and spinal cord of EPO-treated and control mice on day 14 after MOG injection. (partly adapted from Clin Exp Immunol. [Chen et al.])

Furthermore, we observed a greater extent of staining for HO-1-positive splenocytes in EPO-treated MOG-EAE mice than in the controls (Fig. 3a); this was also reflected in a significantly greater mean fluorescence intensity (MFI) in flow cytometry of the splenic lymphocytes of EPO-treated MOG-EAE mice than those of the controls (Fig. 3b). Similarly, we found an increased ratio of encephalitogenic Th1 and Th17 cells in EPO-treated MOGEAE mice, however, only a mildly decreasing trend of splenic Th1 and Th17 cell subsets from EPO-treated MOG-EAE mice was noted. Instead, a significantly high ratio of splenic Th2 (Fig. 3a) was noted in the EPO-treated group than in the controls, and a notably significant elevation of splenic CD25+Foxp3 $3^{+} \mathrm{CD} 4^{+}$cells (Tregs) was observed in the EPOtreated MOG-EAE mice (Fig. 3d).

We observed that the mRNA expression of HO-1 showed a tendency to increase, while the protein expression of HO-1 was notably high in the spinal cord of EPO-treated MOG-EAE; in contrast, a significant elevation of HO-1 mRNA, but no significant expression of HO-1 protein, was observed in the brain of EPO-treated MOG-EAE mice. Currently, Th17 cells are 
(a)
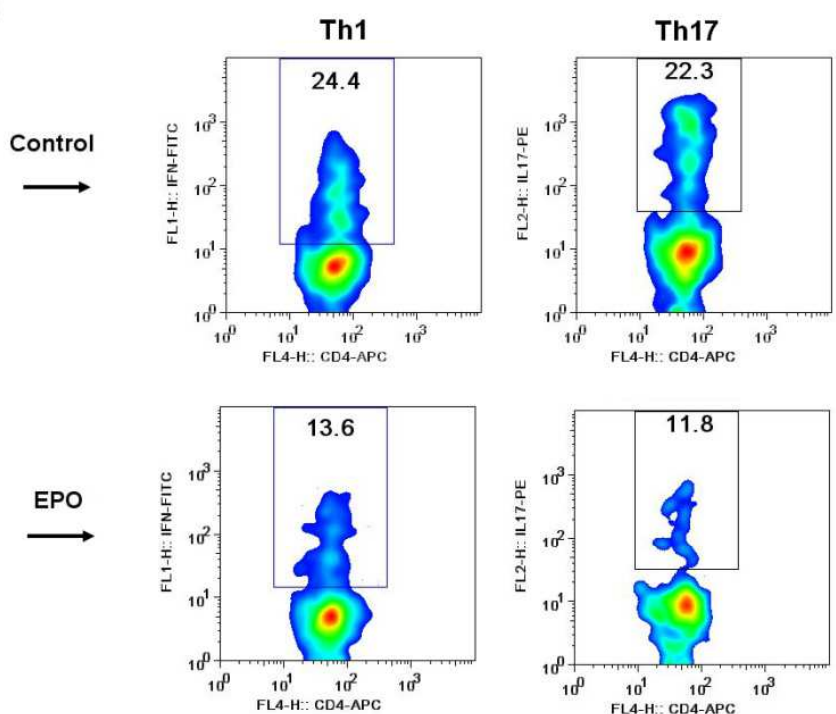

(b)

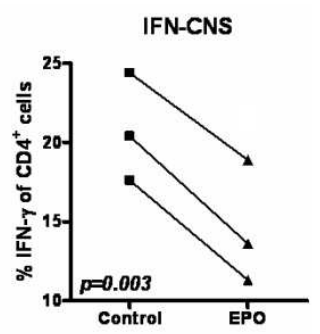

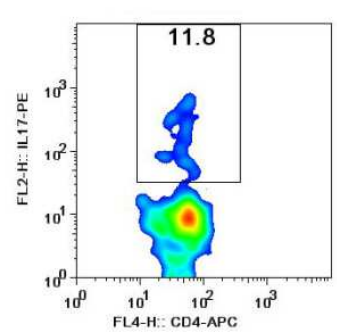

IL17-CNS

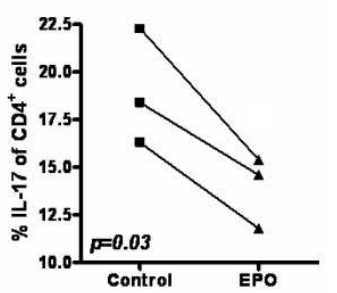

Th2
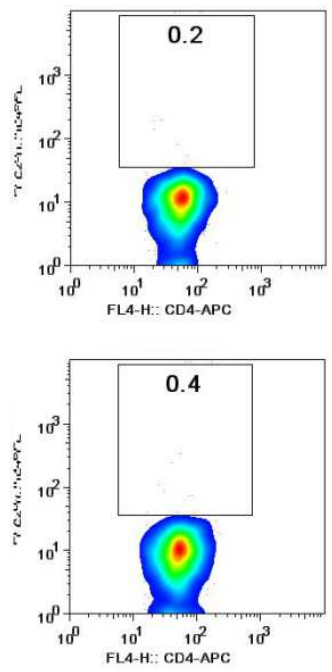

IL4-CNS

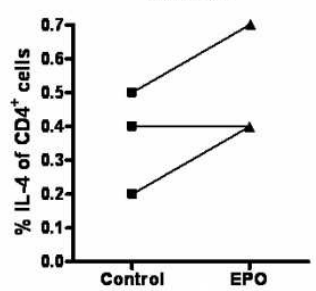

Fig. 2. Distribution of Th lymphocyte subsets in situ. (a) Flow cytometric analysis of intracellular cytokines in CD4 ${ }^{+} \mathrm{T}$ cells isolated from CNS of mice treated with either EPO or PBS. CD4 T lymphocytes isolated from the CNS of EPO-treated mice or controls on day 21 at peak disease stage were intracellularly stained with IL-4, IFN- $\gamma$, and IL-17 by flow cytometry. (b) Percentages of IFN- $\gamma$-producing CD4 ${ }^{+} \mathrm{T}$ cells (Th1), IL-17-producing CD4 ${ }^{+} \mathrm{T}$ cells (Th17), and IL-4-producing CD4 ${ }^{+} \mathrm{T}$ cells (Th2) are presented. Data are representative of 3 experiments. (partly adapted from Clin Exp Immunol. [Chen et al.])

believed to play a vital role in immunopathogenic mechanisms of EAE. However, Th1 cells are required to facilitate the CNS infiltration of Th17 cells in EAE [O'Connor et al., 2008]. Yuan et al. reported that short-tem EPO therapy for EAE can peripherally downregulate MHC class II of DCs and counteract Th17 cell responses [Yuan et al., 2008]. Our data confirmed further that EPO counteracts Th17 and Th1 cell inflammatory responses in EAE, both peripherally and centrally. EPO markedly reduced IL-6 levels in the spinal cord and decreased the inflammation and clinical score of EAE, thereby suggesting that the immunomodulatory activity of EPO may be partly mediated by the reduction of IL-6 levels 
(a)
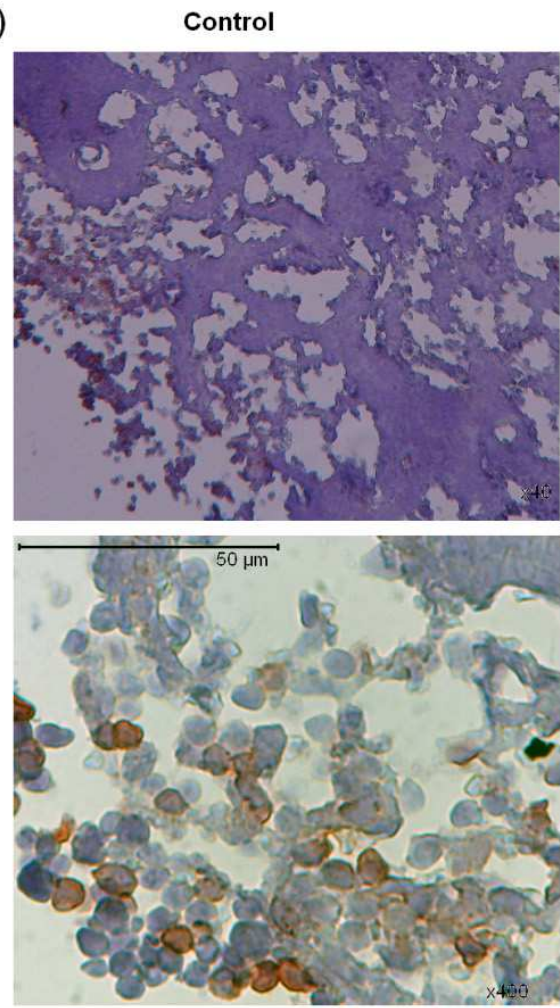

(b)

Expression of $\mathrm{HO}-1$ in Splenic lymphocyte

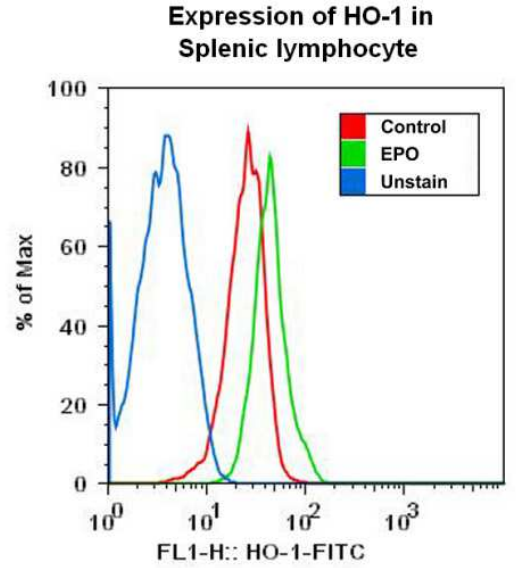

EPO
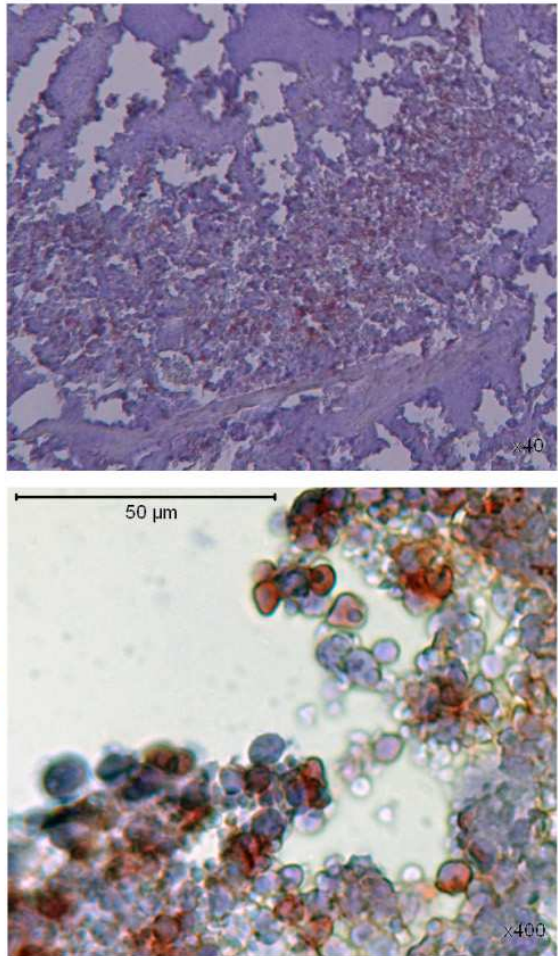

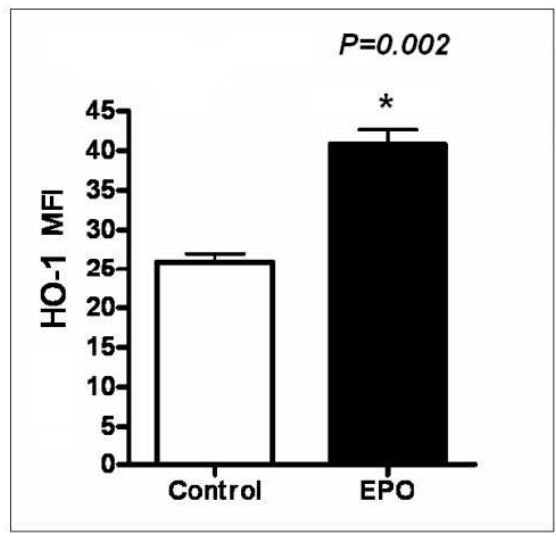


(c)

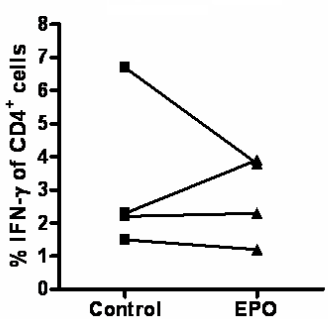

Splenic Th subsets

Th17

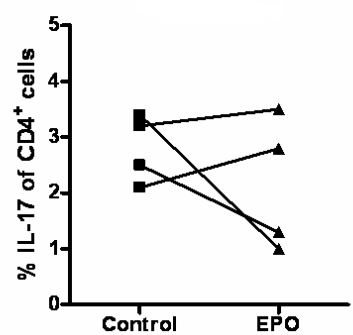

Th2

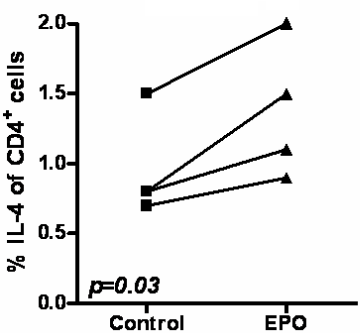

(d)
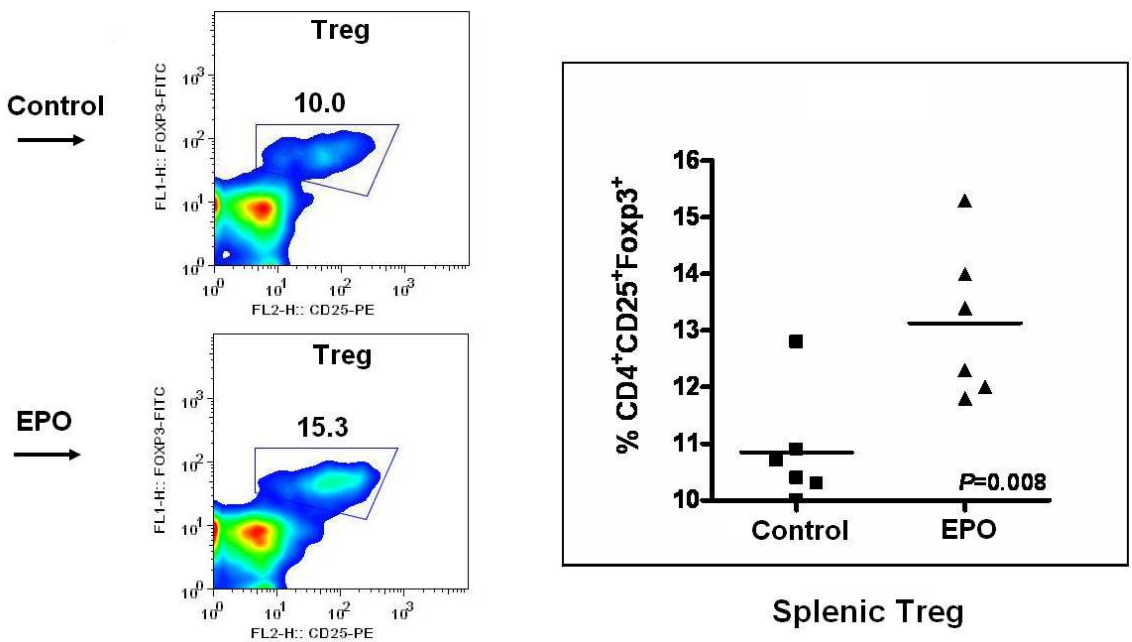

Fig. 3. EPO enhances splenic expression of HO-1, Th2 cells, and Treg.

(a) Immunohistochemical staining for HO-1 expression in the spleen of EPO-treated mice (right) and controls (left) on day 14 after MOG injection. Images are at either $40 \times$ (top) or $400 \times($ bottom) magnification, and the length of the bar represents $50 \mu \mathrm{m}$. (b) Splenic lymphocytes from EPO-treated mice and controls on day 14 of EAE were stained with FITCconjugated HO-1 for flow cytometry. Mean fluorescence intensity (MFI) of HO-1 staining was analyzed (b, left). Representative of 3 experiments. * indicates $p<0.05$. (c) Splenic lymphocytes from EPO-treated mice and from controls were stained for Th1, Th2, and Th17 cells for flow cytometry analysis of the proportion of total CD4 T cells. Data represent 4 experiments. (d) These splenic lymphocytes were also stained for CD25 ${ }^{+} \mathrm{Foxp}^{+} \mathrm{CD}^{+}$cells (Treg) by flow cytometry. Compared to controls, EPO-treated MOG-EAE mice had higher ratio of splenic Treg on day 14. Data of Treg represent 6 experiments. (partly adapted from Clin Exp Immunol. [Chen et al.]) 
[Agnello et al., 2002]. Tron et al. noted that the expression of HO-1 were elevated in a localized inflammation after intramuscular injection of inflammatory material and IL-6specific transcripts were introduced into the injured muscle and were in accordance with the serum levels of IL-6; these findings imply that the induction of HO-1 in local inflammation may affect other anti-inflammatory agents, such as local IL-6 [Tron et al., 2005]. Our data show that there is suppression of IL-6 mRNA in the CNS of EPO-treated MOG-EAE mice, which may be attributed to the overexpression of residential HO-1 to counteract IL-6 (Fig. 2). However, further investigation is required to clarify this.

We confirmed that exogenous EPO promotes the expression of endogenous HO-1, either in the CNS or the spleen, to repress Th1 and Th17 responses in situ and that it enhances the systemic invasion of Th2 and Tregs to reduce the severity of EAE. The potential role of EPO in upregulating the expression of endogenous HO-1 and, thereby, the anti-oxidative and anti-inflammatory activities of HO-1 indicate that EPO may have potential for clinical therapeutic application in autoimmune CNS disorders, such as MS. Taken together, these findings suggested that EPO not only causes the upregulation of HO-1 expression in the CNS but also acts as a potent inducer of HO-1 expression in the peripheral immunologic systems. Collectively, the neuroprotective action of EPO in EAE appears to involve different mechanisms of systemic and local inhibition of inflammation [Chen et al., 2010].

\section{Conclusion}

Patients with MS often experience difficulty in ambulation, spasticity, sensation, and cognition. The year 2010 marked the beginning of the era of oral medications for MS with the introduction of fingolimod [Brinkmann et al., 2010] as the first oral disease-modifying agent for MS. Subsequently other oral agents, including cladribine, teriflunomide, laquinimod, and dimethyl fumarate, as well as the monoclonal antibodies alemtuzumab, daclizumab, and rituximab have been used in MS [Gold, Krieger]. Currently, promising results have been obtained in Phase II trials of teriflunomide, daclizumab, laquinimod, and an antioxidant agent-fumarate [Barten et al., 2010].

However, to date, no specific drugs have been developed to completely cure MS.

Considering the data gathered from studies, such as those on animal models of EAE, it can be inferred that antioxidant molecules may be beneficial to some extent for adjuvant therapy in MS [Mirshafiey and Mohsenzadegan, 2009; van Horssen et al., 2008; van Horssen et al., 2010]. Although some antioxidants have shown some degree of efficacy in EAE, little information is available on the effect of their use in MS [Mirshafiey and Mohsenzadegan, 2009; Schreibelt et al., 2007]. Nevertheless, antioxidant therapy can be considered a candidate for use as adjuvant therapy in MS.

\section{Acknowledgments}

This work was supported by grants from the TSGH-C101-009-S03 and to S.J. Chen, National Science Council, Taiwan, Republic of China (NSC 99-2314-B-016 -002 -MY3 to S.J. Chen) and National Science Council, Taiwan, Republic of China (NSC100-3112-B-016-001 to H.-K. Sytwu). 


\section{References}

Abdul HM, Butterfield DA (2007): Involvement of PI3K/PKG/ERK1/2 signaling pathways in cortical neurons to trigger protection by cotreatment of acetyl-L-carnitine and alpha-lipoic acid against HNE-mediated oxidative stress and neurotoxicity: implications for Alzheimer's disease. Free Radic Biol Med 42:371-84.

Acuna CD, Escames G, Carazo A, Leon J, Khaldy H, Reiter RJ (2002): Melatonin, mitochondrial homeostasis and mitochondrial-related diseases. Curr Top Med Chem 2:133-51.

Agnello D, Bigini P, Villa P, Mennini T, Cerami A, Brines ML, Ghezzi P (2002): Erythropoietin exerts an anti-inflammatory effect on the CNS in a model of experimental autoimmune encephalomyelitis. Brain Res 952:128-34.

Akpinar D, Yargicoglu P, Derin N, Aliciguzel Y, Agar A (2008a): The effect of lipoic acid on antioxidant status and lipid peroxidation in rats exposed to chronic restraint stress. Physiol Res 57:893-901.

Akpinar Z, Tokgoz S, Gokbel H, Okudan N, Uguz F, Yilmaz G (2008b): The association of nocturnal serum melatonin levels with major depression in patients with acute multiple sclerosis. Psychiatry Res 161:253-7.

Aktas O, Prozorovski T, Smorodchenko A, Savaskan NE, Lauster R, Kloetzel PM, InfanteDuarte C, Brocke S, Zipp F (2004): Green tea epigallocatechin-3-gallate mediates T cellular NF-kappa B inhibition and exerts neuroprotection in autoimmune encephalomyelitis. J Immunol 173:5794-800.

Anderson G, Rodriguez M (2011): Multiple sclerosis, seizures, and antiepileptics: role of IL18, IDO, and melatonin. Eur J Neurol 18:680-5.

Bal-Price A, Brown GC (2001): Inflammatory neurodegeneration mediated by nitric oxide from activated glia-inhibiting neuronal respiration, causing glutamate release and excitotoxicity. J Neurosci 21:6480-91.

Barten LJ, Allington DR, Procacci KA, Rivey MP (2010): New approaches in the management of multiple sclerosis. Drug Des Devel Ther 4:343-66.

Bartesaghi S, Marinovich M, Corsini E, Galli CL, Viviani B (2005): Erythropoietin: a novel neuroprotective cytokine. Neurotoxicology 26:923-8.

Bernaudin M, Marti HH, Roussel S, Divoux D, Nouvelot A, MacKenzie ET, Petit E (1999): A potential role for erythropoietin in focal permanent cerebral ischemia in mice. J Cereb Blood Flow Metab 19:643-51.

Bettelli E, Carrier Y, Gao W, Korn T, Strom TB, Oukka M, Weiner HL, Kuchroo VK (2006): Reciprocal developmental pathways for the generation of pathogenic effector TH17 and regulatory T cells. Nature 441:235-8.

Bever CT, Jr., Rosenberg GA (1999): Matrix metalloproteinases in multiple sclerosis: targets of therapy or markers of injury? Neurology 53:1380-1.

Bolanos JP, Almeida A, Stewart V, Peuchen S, Land JM, Clark JB, Heales SJ (1997): Nitric oxide-mediated mitochondrial damage in the brain: mechanisms and implications for neurodegenerative diseases. J Neurochem 68:2227-40.

Brines ML, Ghezzi P, Keenan S, Agnello D, de Lanerolle NC, Cerami C, Itri LM, Cerami A (2000): Erythropoietin crosses the blood-brain barrier to protect against experimental brain injury. Proc Natl Acad Sci U S A 97:10526-31.

Brinkmann V, Billich A, Baumruker T, Heining P, Schmouder R, Francis G, Aradhye S, Burtin P (2010): Fingolimod (FTY720): discovery and development of an oral drug to treat multiple sclerosis. Nat Rev Drug Discov 9:883-97. 
Burger D, Xiang F, Hammoud L, Lu X, Feng Q (2009): Role of heme oxygenase-1 in the cardioprotective effects of erythropoietin during myocardial ischemia and reperfusion. Am J Physiol Heart Circ Physiol 296:H84-93.

Castroviejo DA, Lopez LC, Escames G, Lopez A, Garcia JA, Reiter RJ (2011): Melatoninmitochondria Interplay in Health and Disease. Curr Top Med Chem 11:221-40.

Chaudhary P, Marracci GH, Bourdette DN (2006): Lipoic acid inhibits expression of ICAM-1 and VCAM-1 by CNS endothelial cells and T cell migration into the spinal cord in experimental autoimmune encephalomyelitis. J Neuroimmunol 175:87-96.

Chen SJ, Wang YL, Lo WT, Wu CC, Hsieh CW, Huang CF, Lan YH, Wang CC, Chang DM, Sytwu HK (2010): Erythropoietin enhances endogenous haem oxygenase-1 and represses immune responses to ameliorate experimental autoimmune encephalomyelitis. Clin Exp Immunol 162:210-23.

Cheng PY, Lee YM, Shih NL, Chen YC, Yen MH (2006): Heme oxygenase-1 contributes to the cytoprotection of alpha-lipoic acid via activation of p44/42 mitogen-activated protein kinase in vascular smooth muscle cells. Free Radic Biol Med 40:1313-22.

Chora AA, Fontoura P, Cunha A, Pais TF, Cardoso S, Ho PP, Lee LY, Sobel RA, Steinman L, Soares MP (2007): Heme oxygenase- 1 and carbon monoxide suppress autoimmune neuroinflammation. J Clin Invest 117:438-47.

Colton CA, Gilbert DL (1993): Microglia, an in vivo source of reactive oxygen species in the brain. Adv Neurol 59:321-6.

Constantinescu CS (1995): Melanin, melatonin, melanocyte-stimulating hormone, and the susceptibility to autoimmune demyelination: a rationale for light therapy in multiple sclerosis. Med Hypotheses 45:455-8.

Constantinescu CS, Hilliard B, Ventura E, Rostami A (1997): Luzindole, a melatonin receptor antagonist, suppresses experimental autoimmune encephalomyelitis. Pathobiology 65:190-4.

Crocenzi FA, Roma MG (2006): Silymarin as a new hepatoprotective agent in experimental cholestasis: new possibilities for an ancient medication. Curr Med Chem 13:1055-74.

Cuzzocrea S, Costantino G, Mazzon E, Micali A, De Sarro A, Caputi AP (2000): Beneficial effects of melatonin in a rat model of splanchnic artery occlusion and reperfusion. J Pineal Res 28:52-63.

De Paula ML, Rodrigues DH, Teixeira HC, Barsante MM, Souza MA, Ferreira AP (2008): Genistein down-modulates pro-inflammatory cytokines and reverses clinical signs of experimental autoimmune encephalomyelitis. Int Immunopharmacol 8:1291-7.

Diaz Z, Assaraf MI, Miller WH, Jr., Schipper HM (2005): Astroglial cytoprotection by erythropoietin pre-conditioning: implications for ischemic and degenerative CNS disorders. J Neurochem 93:392-402.

Digicaylioglu M, Lipton SA (2001): Erythropoietin-mediated neuroprotection involves crosstalk between Jak2 and NF-kappaB signalling cascades. Nature 412:641-7.

Ehrenreich H, Fischer B, Norra C, Schellenberger F, Stender N, Stiefel M, Siren AL, Paulus W, Nave KA, Gold R, Bartels C (2007): Exploring recombinant human erythropoietin in chronic progressive multiple sclerosis. Brain 130:2577-88.

Emerit J, Edeas M, Bricaire F (2004): Neurodegenerative diseases and oxidative stress. Biomed Pharmacother 58:39-46.

Emerson MR, LeVine SM (2000): Heme oxygenase-1 and NADPH cytochrome P450 reductase expression in experimental allergic encephalomyelitis: an expanded view of the stress response. J Neurochem 75:2555-62. 
Endoh M, Maiese K, Wagner J (1994): Expression of the inducible form of nitric oxide synthase by reactive astrocytes after transient global ischemia. Brain Res 651:92-100.

Endres M (2006): Statins: potential new indications in inflammatory conditions. Atheroscler Suppl 7:31-5.

Esposito E, Cuzzocrea S (2010): Antiinflammatory activity of melatonin in central nervous system. Curr Neuropharmacol 8:228-42.

Ferguson B, Matyszak MK, Esiri MM, Perry VH (1997): Axonal damage in acute multiple sclerosis lesions. Brain 120 ( Pt 3):393-9.

Floyd RA, Carney JM (1993): The role of metal ions in oxidative processes and aging. Toxicol Ind Health 9:197-214.

Floyd RA, Hensley K (2002): Oxidative stress in brain aging. Implications for therapeutics of neurodegenerative diseases. Neurobiol Aging 23:795-807.

Frohman EM, Racke MK, Raine CS (2006): Multiple sclerosis--the plaque and its pathogenesis. N Engl J Med 354:942-55.

Gilad E, Wong HR, Zingarelli B, Virag L, O'Connor M, Salzman AL, Szabo C (1998): Melatonin inhibits expression of the inducible isoform of nitric oxide synthase in murine macrophages: role of inhibition of NFkappaB activation. Faseb J 12:685-93.

Gilgun-Sherki Y, Melamed E, Offen D (2004): The role of oxidative stress in the pathogenesis of multiple sclerosis: the need for effective antioxidant therapy. J Neurol 251:261-8.

Gohil K, Roy S, Packer L, Sen CK (1999): Antioxidant regulation of gene expression: analysis of differentially expressed mRNAs. Methods Enzymol 300:402-10.

Gold R (2011): Oral therapies for multiple sclerosis: a review of agents in phase III development or recently approved. CNS Drugs 25:37-52.

Golde S, Chandran S, Brown GC, Compston A (2002): Different pathways for iNOSmediated toxicity in vitro dependent on neuronal maturation and NMDA receptor expression. J Neurochem 82:269-82.

Gray E, Thomas TL, Betmouni S, Scolding N, Love S (2008): Elevated activity and microglial expression of myeloperoxidase in demyelinated cerebral cortex in multiple sclerosis. Brain Pathol 18:86-95.

Gunnarson E, Song Y, Kowalewski JM, Brismar H, Brines M, Cerami A, Andersson U, Zelenina M, Aperia A (2009): Erythropoietin modulation of astrocyte water permeability as a component of neuroprotection. Proc Natl Acad Sci U S A 106:1602-7.

Hendriks JJ, Alblas J, van der Pol SM, van Tol EA, Dijkstra CD, de Vries HE (2004): Flavonoids influence monocytic GTPase activity and are protective in experimental allergic encephalitis. J Exp Med 200:1667-72.

Hendriks JJ, de Vries HE, van der Pol SM, van den Berg TK, van Tol EA, Dijkstra CD (2003): Flavonoids inhibit myelin phagocytosis by macrophages; a structure-activity relationship study. Biochem Pharmacol 65:877-85.

Hill JM, Switzer RC, 3rd (1984): The regional distribution and cellular localization of iron in the rat brain. Neuroscience 11:595-603.

Hisahara S, Okano H, Miura M (2003): Caspase-mediated oligodendrocyte cell death in the pathogenesis of autoimmune demyelination. Neurosci Res 46:387-97.

Hutter CD, Laing P (1996): Multiple sclerosis: sunlight, diet, immunology and aetiology. Med Hypotheses 46:67-74.

Johnson JA, Johnson DA, Kraft AD, Calkins MJ, Jakel RJ, Vargas MR, Chen PC (2008): The Nrf2-ARE pathway: an indicator and modulator of oxidative stress in neurodegeneration. Ann N Y Acad Sci 1147:61-9. 
Kalman B, Laitinen K, Komoly S (2007): The involvement of mitochondria in the pathogenesis of multiple sclerosis. J Neuroimmunol 188:1-12.

Kang JC, Ahn M, Kim YS, Moon C, Lee Y, Wie MB, Lee YJ, Shin T (2001): Melatonin ameliorates autoimmune encephalomyelitis through suppression of intercellular adhesion molecule-1. J Vet Sci 2:85-9.

Kaur C, Ling EA (2008): Antioxidants and neuroprotection in the adult and developing central nervous system. Curr Med Chem 15:3068-80.

Kornek B, Storch MK, Weissert R, Wallstroem E, Stefferl A, Olsson T, Linington C, Schmidbauer M, Lassmann H (2000): Multiple sclerosis and chronic autoimmune encephalomyelitis: a comparative quantitative study of axonal injury in active, inactive, and remyelinated lesions. Am J Pathol 157:267-76.

Krieger S (2011): Multiple sclerosis therapeutic pipeline: opportunities and challenges. Mt Sinai J Med 78:192-206.

Kumral A, Baskin H, Gokmen N, Yilmaz O, Genc K, Genc S, Tatli MM, Duman N, Ozer E, Ozkan H (2004): Selective inhibition of nitric oxide in hypoxic-ischemic brain model in newborn rats: is it an explanation for the protective role of erythropoietin? Biol Neonate 85:51-4.

Lee JM, Li J, Johnson DA, Stein TD, Kraft AD, Calkins MJ, Jakel RJ, Johnson JA (2005): Nrf2, a multi-organ protector? Faseb J 19:1061-6.

Lee S, Suk K (2007): Heme oxygenase-1 mediates cytoprotective effects of immunostimulation in microglia. Biochem Pharmacol 74:723-9.

Lee TS, Chau LY (2002): Heme oxygenase-1 mediates the anti-inflammatory effect of interleukin-10 in mice. Nat Med 8:240-6.

Leist M, Ghezzi P, Grasso G, Bianchi R, Villa P, Fratelli M, Savino C, Bianchi M, Nielsen J, Gerwien J, Kallunki P, Larsen AK, Helboe L, Christensen S, Pedersen LO, Nielsen M, Torup L, Sager T, Sfacteria A, Erbayraktar S, Erbayraktar Z, Gokmen N, Yilmaz O, Cerami-Hand C, Xie QW, Coleman T, Cerami A, Brines M (2004): Derivatives of erythropoietin that are tissue protective but not erythropoietic. Science 305:239-42.

Lifshitz L, Prutchi-Sagiv S, Avneon M, Gassmann M, Mittelman M, Neumann D (2009): Non-erythroid activities of erythropoietin: Functional effects on murine dendritic cells. Mol Immunol 46:713-21.

Lin GJ, Huang SH, Chen YW, Hueng DY, Chien MW, Chia WT, Chang DM, Sytwu HK (2009): Melatonin prolongs islet graft survival in diabetic NOD mice. J Pineal Res 47:284-92.

Lin RF, Lin TS, Tilton RG, Cross AH (1993): Nitric oxide localized to spinal cords of mice with experimental allergic encephalomyelitis: an electron paramagnetic resonance study. J Exp Med 178:643-8.

Linker RA, Lee DH, Ryan S, van Dam AM, Conrad R, Bista P, Zeng W, Hronowsky X, Buko A, Chollate S, Ellrichmann G, Bruck W, Dawson K, Goelz S, Wiese S, Scannevin RH, Lukashev M, Gold R (2011): Fumaric acid esters exert neuroprotective effects in neuroinflammation via activation of the Nrf2 antioxidant pathway. Brain 134:678-92.

Liu Y, Zhu B, Luo L, Li P, Paty DW, Cynader MS (2001): Heme oxygenase-1 plays an important protective role in experimental autoimmune encephalomyelitis. Neuroreport 12:1841-5.

Liuzzi GM, Latronico T, Brana MT, Gramegna P, Coniglio MG, Rossano R, Larocca M, Riccio P (2011): Structure-dependent inhibition of gelatinases by dietary 
antioxidants in rat astrocytes and sera of multiple sclerosis patients. Neurochem Res 36:518-27.

Maestroni GJ (1995): T-helper-2 lymphocytes as a peripheral target of melatonin. J Pineal Res 18:84-9.

Mahad DJ, Ziabreva I, Campbell G, Lax N, White K, Hanson PS, Lassmann H, Turnbull DM (2009): Mitochondrial changes within axons in multiple sclerosis. Brain 132:1161-74.

Maiese K, Li F, Chong ZZ (2004): Erythropoietin in the brain: can the promise to protect be fulfilled? Trends Pharmacol Sci 25:577-83.

Mander P, Borutaite V, Moncada S, Brown GC (2005): Nitric oxide from inflammatoryactivated glia synergizes with hypoxia to induce neuronal death. J Neurosci Res 79:208-15.

Mandler RN, Dencoff JD, Midani F, Ford CC, Ahmed W, Rosenberg GA (2001): Matrix metalloproteinases and tissue inhibitors of metalloproteinases in cerebrospinal fluid differ in multiple sclerosis and Devic's neuromyelitis optica. Brain 124:493-8.

Marangon K, Devaraj S, Tirosh O, Packer L, Jialal I (1999): Comparison of the effect of alphalipoic acid and alpha-tocopherol supplementation on measures of oxidative stress. Free Radic Biol Med 27:1114-21.

Marracci GH, Jones RE, McKeon GP, Bourdette DN (2002): Alpha lipoic acid inhibits T cell migration into the spinal cord and suppresses and treats experimental autoimmune encephalomyelitis. J Neuroimmunol 131:104-14.

Marracci GH, McKeon GP, Marquardt WE, Winter RW, Riscoe MK, Bourdette DN (2004): Alpha lipoic acid inhibits human T-cell migration: implications for multiple sclerosis. J Neurosci Res 78:362-70.

Martin D, Rojo AI, Salinas M, Diaz R, Gallardo G, Alam J, De Galarreta CM, Cuadrado A (2004): Regulation of heme oxygenase-1 expression through the phosphatidylinositol 3-kinase/Akt pathway and the Nrf2 transcription factor in response to the antioxidant phytochemical carnosol. J Biol Chem 279:8919-29.

Martin M, Macias M, Escames G, Leon J, Acuna-Castroviejo D (2000): Melatonin but not vitamins $\mathrm{C}$ and $\mathrm{E}$ maintains glutathione homeostasis in t-butyl hydroperoxideinduced mitochondrial oxidative stress. Faseb J 14:1677-9.

Min K, Yoon WK, Kim SK, Kim BH (2007): Immunosuppressive effect of silibinin in experimental autoimmune encephalomyelitis. Arch Pharm Res 30:1265-72.

Mirshafiey A, Mohsenzadegan M (2009): Antioxidant therapy in multiple sclerosis. Immunopharmacol Immunotoxicol 31:13-29.

Moi P, Chan K, Asunis I, Cao A, Kan YW (1994): Isolation of NF-E2-related factor 2 (Nrf2), a NF-E2-like basic leucine zipper transcriptional activator that binds to the tandem NF-E2/AP1 repeat of the beta-globin locus control region. Proc Natl Acad Sci U S A 91:9926-30.

Moini H, Packer L, Saris NE (2002): Antioxidant and prooxidant activities of alpha-lipoic acid and dihydrolipoic acid. Toxicol Appl Pharmacol 182:84-90.

Mori A, Yokoi I, Noda Y, Willmore LJ (2004): Natural antioxidants may prevent posttraumatic epilepsy: a proposal based on experimental animal studies. Acta Med Okayama 58:111-8.

Morini M, Roccatagliata L, Dell'Eva R, Pedemonte E, Furlan R, Minghelli S, Giunti D, Pfeffer U, Marchese M, Noonan D, Mancardi G, Albini A, Uccelli A (2004): Alpha-lipoic acid is effective in prevention and treatment of experimental autoimmune encephalomyelitis. J Neuroimmunol 148:146-53. 
Murakami A (2009): Chemoprevention with phytochemicals targeting inducible nitric oxide synthase. Forum Nutr 61:193-203.

Murphy MP (1999): Nitric oxide and cell death. Biochim Biophys Acta 1411:401-14.

Nath N, Giri S, Prasad R, Singh AK, Singh I (2004): Potential targets of 3-hydroxy-3methylglutaryl coenzyme A reductase inhibitor for multiple sclerosis therapy. J Immunol 172:1273-86.

O'Connor RA, Prendergast CT, Sabatos CA, Lau CW, Leech MD, Wraith DC, Anderton SM (2008): Cutting edge: Th1 cells facilitate the entry of Th17 cells to the central nervous system during experimental autoimmune encephalomyelitis. J Immunol 181:3750-4.

Okuda Y, Sakoda S, Fujimura H, Yanagihara T (1997): Nitric oxide via an inducible isoform of nitric oxide synthase is a possible factor to eliminate inflammatory cells from the central nervous system of mice with experimental allergic encephalomyelitis. J Neuroimmunol 73:107-16.

Pahan K, Sheikh FG, Namboodiri AM, Singh I (1997): Lovastatin and phenylacetate inhibit the induction of nitric oxide synthase and cytokines in rat primary astrocytes, microglia, and macrophages. J Clin Invest 100:2671-9.

Panahian N, Yoshiura M, Maines MD (1999): Overexpression of heme oxygenase-1 is neuroprotective in a model of permanent middle cerebral artery occlusion in transgenic mice. J Neurochem 72:1187-203.

Paz Soldan MM, Pittock SJ, Weigand SD, Yawn BP, Rodriguez M (2011): Statin therapy and multiple sclerosis disability in a population-based cohort. Mult Scler. Epub ahead of print.

Pierpaoli W, Regelson W (1994): Pineal control of aging: effect of melatonin and pineal grafting on aging mice. Proc Natl Acad Sci U S A 91:787-91.

Ponomarev ED, Maresz K, Tan Y, Dittel BN (2007): CNS-derived interleukin-4 is essential for the regulation of autoimmune inflammation and induces a state of alternative activation in microglial cells. J Neurosci 27:10714-21.

Prawan A, Kundu JK, Surh YJ (2005): Molecular basis of heme oxygenase-1 induction: implications for chemoprevention and chemoprotection. Antioxid Redox Signal 7:1688-703.

Reiter RJ (1995a): Functional pleiotropy of the neurohormone melatonin: antioxidant protection and neuroendocrine regulation. Front Neuroendocrinol 16:383-415.

Reiter RJ (1995b): Oxidative processes and antioxidative defense mechanisms in the aging brain. Faseb J 9:526-33.

Reiter RJ, Tan DX, Manchester LC, Tamura H (2007): Melatonin defeats neurally-derived free radicals and reduces the associated neuromorphological and neurobehavioral damage. J Physiol Pharmacol 58 Suppl 6:5-22.

Rushmore TH, Morton MR, Pickett CB (1991): The antioxidant responsive element. Activation by oxidative stress and identification of the DNA consensus sequence required for functional activity. J Biol Chem 266:11632-9.

Rushmore TH, Pickett CB (1990): Transcriptional regulation of the rat glutathione Stransferase Ya subunit gene. Characterization of a xenobiotic-responsive element controlling inducible expression by phenolic antioxidants. J Biol Chem 265:1464853.

Sandyk R (1997): Influence of the pineal gland on the expression of experimental allergic encephalomyelitis: possible relationship to the acquisition of multiple sclerosis. Int J Neurosci 90:129-33. 
Sattler MB, Merkler D, Maier K, Stadelmann C, Ehrenreich H, Bahr M, Diem R (2004): Neuroprotective effects and intracellular signaling pathways of erythropoietin in a rat model of multiple sclerosis. Cell Death Differ 11 Suppl 2:S181-92.

Schipper HM (2004): Heme oxygenase-1: transducer of pathological brain iron sequestration under oxidative stress. Ann N Y Acad Sci 1012:84-93.

Schluesener HJ, Seid K (2000): Heme oxygenase-1 in lesions of rat experimental autoimmune encephalomyelitis and neuritis. J Neuroimmunol 110:114-20.

Schreibelt G, Musters RJ, Reijerkerk A, de Groot LR, van der Pol SM, Hendrikx EM, Dopp ED, Dijkstra CD, Drukarch B, de Vries HE (2006): Lipoic acid affects cellular migration into the central nervous system and stabilizes blood-brain barrier integrity. J Immunol 177:2630-7.

Schreibelt G, van Horssen J, van Rossum S, Dijkstra CD, Drukarch B, de Vries HE (2007): Therapeutic potential and biological role of endogenous antioxidant enzymes in multiple sclerosis pathology. Brain Res Rev 56:322-30.

Schreiner B, Heppner FL, Becher B (2009): Modeling multiple sclerosis in laboratory animals. Semin Immunopathol 31:479-95.

Sorensen PS, Lycke J, Eralinna JP, Edland A, Wu X, Frederiksen JL, Oturai A, Malmestrom C, Stenager E, Sellebjerg F, Sondergaard HB (2011): Simvastatin as add-on therapy to interferon beta-1a for relapsing-remitting multiple sclerosis (SIMCOMBIN study): a placebo-controlled randomised phase 4 trial. Lancet Neurol 10:691-701.

Stanislaus R, Pahan K, Singh AK, Singh I (1999): Amelioration of experimental allergic encephalomyelitis in Lewis rats by lovastatin. Neurosci Lett 269:71-4.

Sternberg Z, Chadha K, Lieberman A, Hojnacki D, Drake A, Zamboni P, Rocco P, Grazioli E, Weinstock-Guttman B, Munschauer F (2008): Quercetin and interferon-beta modulate immune response(s) in peripheral blood mononuclear cells isolated from multiple sclerosis patients. J Neuroimmunol 205:142-7.

Su KG, Banker G, Bourdette D, Forte M (2009): Axonal degeneration in multiple sclerosis: the mitochondrial hypothesis. Curr Neurol Neurosci Rep 9:411-7.

Sueoka N, Suganuma M, Sueoka E, Okabe S, Matsuyama S, Imai K, Nakachi K, Fujiki H (2001): A new function of green tea: prevention of lifestyle-related diseases. Ann N Y Acad Sci 928:274-80.

Taupin P (2008): Adult neurogenesis, neuroinflammation and therapeutic potential of adult neural stem cells. Int J Med Sci 5:127-32.

Theoharides TC (2009): Luteolin as a therapeutic option for multiple sclerosis. J Neuroinflammation 6:29.

Tirosh O, Sen CK, Roy S, Kobayashi MS, Packer L (1999): Neuroprotective effects of alphalipoic acid and its positively charged amide analogue. Free Radic Biol Med 26:141826.

Trapp BD, Peterson J, Ransohoff RM, Rudick R, Mork S, Bo L (1998): Axonal transection in the lesions of multiple sclerosis. N Engl J Med 338:278-85.

Tron K, Novosyadlyy R, Dudas J, Samoylenko A, Kietzmann T, Ramadori G (2005): Upregulation of heme oxygenase-1 gene by turpentine oil-induced localized inflammation: involvement of interleukin-6. Lab Invest 85:376-87.

Tzima S, Victoratos P, Kranidioti K, Alexiou M, Kollias G (2009): Myeloid heme oxygenase-1 regulates innate immunity and autoimmunity by modulating IFN-beta production. J Exp Med 206:1167-79. 
van der Goes A, Brouwer J, Hoekstra K, Roos D, van den Berg TK, Dijkstra CD (1998): Reactive oxygen species are required for the phagocytosis of myelin by macrophages. J Neuroimmunol 92:67-75.

van der Valk P, De Groot CJ (2000): Staging of multiple sclerosis (MS) lesions: pathology of the time frame of MS. Neuropathol Appl Neurobiol 26:2-10.

van Horssen J, Drexhage JA, Flor T, Gerritsen W, van der Valk P, de Vries HE (2010): Nrf2 and DJ1 are consistently upregulated in inflammatory multiple sclerosis lesions. Free Radic Biol Med 49:1283-9.

van Horssen J, Schreibelt G, Drexhage J, Hazes T, Dijkstra CD, van der Valk P, de Vries HE (2008): Severe oxidative damage in multiple sclerosis lesions coincides with enhanced antioxidant enzyme expression. Free Radic Biol Med 45:1729-37.

van Horssen J, Witte ME, Schreibelt G, de Vries HE (2011): Radical changes in multiple sclerosis pathogenesis. Biochim Biophys Acta 1812:141-50.

van Meeteren ME, Teunissen CE, Dijkstra CD, van Tol EA (2005): Antioxidants and polyunsaturated fatty acids in multiple sclerosis. Eur J Clin Nutr 59:1347-61.

Venugopal R, Jaiswal AK (1996): Nrf1 and Nrf2 positively and c-Fos and Fra1 negatively regulate the human antioxidant response element-mediated expression of NAD(P)H:quinone oxidoreductase1 gene. Proc Natl Acad Sci U S A 93:14960-5.

Verbeek R, van Tol EA, van Noort JM (2005): Oral flavonoids delay recovery from experimental autoimmune encephalomyelitis in SJL mice. Biochem Pharmacol 70:220-8.

Weber MS, Zamvil SS (2008): Statins and demyelination. Curr Top Microbiol Immunol 318:313-24.

Witte ME, Bo L, Rodenburg RJ, Belien JA, Musters R, Hazes T, Wintjes LT, Smeitink JA, Geurts JJ, De Vries HE, van der Valk P, van Horssen J (2009): Enhanced number and activity of mitochondria in multiple sclerosis lesions. J Pathol 219:193-204.

Wu CC, Lu KC, Chen JS, Hsieh HY, Lin SH, Chu P, Wang JY, Sytwu HK, Lin YF (2008): HO1 induction ameliorates experimental murine membranous nephropathy: antioxidative, anti-apoptotic and immunomodulatory effects. Nephrol Dial Transplant 23:3082-90.

Youssef S, Stuve O, Patarroyo JC, Ruiz PJ, Radosevich JL, Hur EM, Bravo M, Mitchell DJ, Sobel RA, Steinman L, Zamvil SS (2002): The HMG-CoA reductase inhibitor, atorvastatin, promotes a Th2 bias and reverses paralysis in central nervous system autoimmune disease. Nature 420:78-84.

Yuan R, Maeda Y, Li W, Lu W, Cook S, Dowling P (2008): Erythropoietin: a potent inducer of peripheral immuno/inflammatory modulation in autoimmune EAE. PLoS ONE 3:e1924.

Zenclussen ML, Anegon I, Bertoja AZ, Chauveau C, Vogt K, Gerlof K, Sollwedel A, Volk HD, Ritter T, Zenclussen AC (2006): Over-expression of heme oxygenase-1 by adenoviral gene transfer improves pregnancy outcome in a murine model of abortion. J Reprod Immunol 69:35-52.

Zhang J, Li Y, Cui Y, Chen J, Lu M, Elias SB, Chopp M (2005): Erythropoietin treatment improves neurological functional recovery in EAE mice. Brain Res 1034:34-9.

Zwerina J, Tzima S, Hayer S, Redlich K, Hoffmann O, Hanslik-Schnabel B, Smolen JS, Kollias G, Schett G (2005): Heme oxygenase 1 (HO-1) regulates osteoclastogenesis and bone resorption. Faseb J 19:2011-3. 


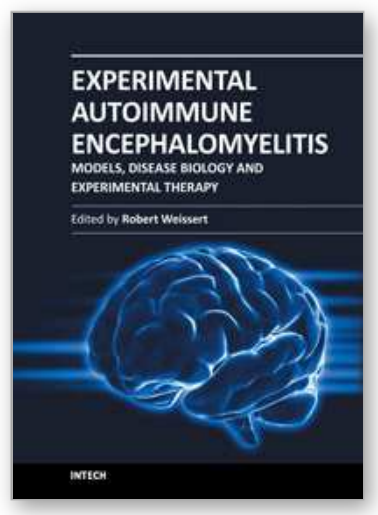

\author{
Experimental Autoimmune Encephalomyelitis - Models, Disease \\ Biology and Experimental Therapy \\ Edited by Prof. Robert Weissert
}

ISBN 978-953-51-0038-6

Hard cover, 162 pages

Publisher InTech

Published online 03, February, 2012

Published in print edition February, 2012

Experimental Autoimmune Encephalomyelitis - Models, Disease Biology and Experimental Therapy is totally focused on the model of multiple sclerosis, experimental autoimmune encephalomyelitis (EAE). The book chapters give a very good and in depth overview about the currently existing and most used EAE models. In addition, chapters dealing with novel experimental therapeutic approaches demonstrate the usefulness of the EAE model for MS research. With an international perspective, this book features contributions from authors throughout the world, Australia, Germany, Japan, Spain, Taiwan, and USA. There is an impressive international Faculty that provides insight into current research themes. This further demonstrates the importance of EAE in research all over the world. The book will provide established researchers and students with novel insights and guidance for their research and will help to push the field forward.

\title{
How to reference
}

In order to correctly reference this scholarly work, feel free to copy and paste the following:

Shyi-Jou Chen Hueng-Chuen Fan and Huey-Kang Sytwu (2012). Immunomodulation of Potent Antioxidant Agents: Preclinical Study to Clinical Application in Multiple Sclerosis, Experimental Autoimmune Encephalomyelitis - Models, Disease Biology and Experimental Therapy, Prof. Robert Weissert (Ed.), ISBN: 978-953-51-0038-6, InTech, Available from: http://www.intechopen.com/books/experimental-autoimmuneencephalomyelitis-models-disease-biology-and-experimental-therapy/immunomodulation-of-potentantioxidant-agents-from-preclinical-study-to-clinical-application-on-mult

\section{INTECH}

open science | open minds

\section{InTech Europe}

University Campus STeP Ri

Slavka Krautzeka 83/A

51000 Rijeka, Croatia

Phone: +385 (51) 770447

Fax: +385 (51) 686166

www.intechopen.com

\section{InTech China}

Unit 405, Office Block, Hotel Equatorial Shanghai

No.65, Yan An Road (West), Shanghai, 200040, China

中国上海市延安西路65号上海国际贵都大饭店办公楼405单元

Phone: +86-21-62489820

Fax: $+86-21-62489821$ 
(C) 2012 The Author(s). Licensee IntechOpen. This is an open access article distributed under the terms of the Creative Commons Attribution 3.0 License, which permits unrestricted use, distribution, and reproduction in any medium, provided the original work is properly cited. 